\title{
From Research to Practice: Designing a Treatment Program for Individuals Convicted of Child Sexual Exploitation Material
}

\author{
Allen Azizian* \\ Department of Criminology, California State University, Fresno
}

Article Info

\section{Article Notes}

Received: May 10, 2021

Accepted: June 02, 2021

\section{*Correspondence:}

Dr. Allen Azizian, PhD, Assistant Professor, 2576 E San Ramon, MS/ST104, Fresno, CA 93740; Telephone Number: (559) 278 2305; Email: aazizian@csufresno.edu.

(c) 2021 Azizian A. This article is distributed under the terms of the Creative Commons Attribution 4.0 International License.

\section{Keywords:}

Child Sexual Exploitation Material

CSEM

Risk Assessment

Treatment

Curriculum

Case Conceptualization

Motivation-Facilitation Model
Abstract

The term evidence-based is increasingly found in treatment manuals and program titles designed for individuals convicted of a sexual offense. However, whether the presented evidence truly qualifies as "evidence-based" is questionable. I will share my experience as the clinical director for a private outpatient agency where we designed a program based on the existing peerreviewed literature on individuals convicted of Child Sexual Exploitation Material (CSEM) offenses. I will describe the steps that we followed in developing a workgroup to explore and apply the knowledge from research to our clinical practice. We adapted the term evidence-informed to acknowledge that the program relied on existing literature in combination with the experiences and expertise of our clinical team. A fictitious case that reflects an amalgamation of facts is presented to demonstrate the assessment and treatment processes. Implications for organizational consensus to conduct program evaluation and research are discussed.

\section{Problematic Use of the Internet}

Access to and regular use of the Internet have increased rapidly in recent years, with 5.11 billion unique mobile users in the world that grow daily ${ }^{1}$. Convenience, connectedness, affordability, creativity, education, entrepreneurship, and cultural exchanges are just a few of the common ways the Internet has changed every aspect of our lives. Similar to other technologies, however, the Internet can be misused, bringing harm to oneself and to others. There is growing concern that for some people, Internet use has become compulsive, excessively time consuming, costly, and ultimately disruptive to other important life domains. The Internet also has facilitated the proliferation of a new form of sex crime - the production, distribution, and consumption of child sexual exploitation materials (CSEM). Internet crimes against children are not limited to sexual abuse images, and other forms of abuse include online grooming of minors and sex tourism. Although these forms of abuse have been around for a long time, the rapid growth of the Internet has afforded unprecedented opportunity to produce, use, share, and sell these images. These opportunities are further advanced through its growing capacity to transmit information through websites, email, instant messaging, newsgroups, bulletin boards, peer-topeer file sharing networks, gaming, social networking sites, and other anonymized networks. Internet-related sex offenses are also facilitated through a concept that Cooper (1998) 2 introduced to the field as the Triple-A Engine: accessibility (24 hours a day, 7 days a week), affordability (free sexual material), and anonymity (perceived belief that online activities are anonymous). 


\section{Magnitude of the Problem}

While the exact prevalence of child abuse images is unknown, estimates from arrest, victimization, and self-report findings suggest that viewing child abuse images is a serious problem and that the numbers are rapidly increasing over time. In 2019, the Internet Watch Foundation, a charity organization that works to remove child sexual abuse content on the Internet, processed about 132,000 online images containing child sexual abuse material - double the number identified online in $2016^{3}$. The National Center for Missing \& Exploited Children ${ }^{4}$ (NCMEC) CyberTipline - a centralized reporting system for the online exploitation of children - has received more than 65 million suspected reports of Internet child sexual exploitation since its inception in 1998. Through NCMEC, more than 18,900 of the victims depicted in abusive images have been identified by law enforcement. Takedown operations of websites that produce and distribute child sexual abuse images are reported regularly in media, with a recent one involving the arrest of 330 individuals for their involvement with a site that contained more than 250,000 unique child abuse videos ${ }^{5}$. In the United States, the number of men incarcerated for child sexual abuse images has nearly doubled since 2004, with most serving mandatory sentences of five years or more. In 2006, there were an estimated 3,672 arrests for crimes involving CSEM possession - more than twice the estimated 1,713 arrests in $2000^{6}$. There are also reports that the victims depicted in these images have become younger, and the images more brutal ${ }^{7-9}$.

\section{Rehabilitation}

In the United States, the criminal justice system is characterized as a swinging pendulum, alternating between punishment and rehabilitation $\operatorname{eras}^{10}$. One recent example is the shift from tough-on-crime toward smart-on-crime that resulted in early release and reentry programs. Today, correctional facilities in most developed countries recognize the value in rehabilitation and helping incarcerated individuals live a law-abiding life following their release from prison. The extensive work of Gendreau and colleagues ${ }^{11,53}$, and replicated across independent investigators ${ }^{12,13}$, is paramount in showing that punishment alone does not reduce crime, but rather that on average, rehabilitation does reduce recidivism, at least to a modest degree. Moreover, rehabilitative outcomes are enhanced with programs that adhere to RiskNeed-Responsivity (RNR) principles ${ }^{14}$. Psychotherapy and counseling are considered integral components of the rehabilitation process, and there are treatment programs designed for individuals who struggle with substance abuse, anger management, and domestic abuse, as well as those convicted of sexual offenses. Traditionally - and arguably still a dominant practice today - the treatment needs of individuals who commit Internet sexual offenses are addressed using standard, or contact ("hands-on"), sex offender treatment methods. With the increase in the number of Internet sexual offenses, however, questions have been raised as to whether individuals convicted of these offenses belong to a separate group of sexual offenders or if they are no different than those convicted of conventional sexual offenses, other than using technology to carry out their offending behavior ${ }^{15}$. Research has demonstrated that individuals convicted of CSEM offenses are different from those convicted of hands-on offenses in demographic, psychosocial characteristics, personality, and coping style ${ }^{16,17}$. Given these initial findings, a key question is how conventional sex offender treatment interventions apply to individuals convicted of CSEM?

\section{Individuals Convicted of an Internet Sex Offense}

Internet sexual offending comprises a range of crimes, including possession, distribution, and production of child sexual abuse images, sexual solicitation of minors, prostitution, and indecent exposure. However, the large majority - and arguably most concerning - involves child pornography. The heterogeneity of Internet sexual offending is complicated further by online, offline, and mixed offending modalities. Questions about the generalizability of the curriculum to address distinct and overlapping treatment needs arose in the early stages of the curriculum development. Our efforts to customize the program for individuals convicted of Internet sex offenses centered on maintaining adherence to RNR principles, as well as the emerging research demonstrating psychological difference among those who have committed Internet sex offenses ${ }^{18}$. Research thus far has identified three types of sexual offending against children with unique and overlapping characteristics: individuals convicted of CSEM (online) offenses, individuals convicted of typical (offline) sex offenses, and individuals convicted of offenses with both CSEM and contact (mixed) offenses. Individuals convicted of child pornography-only offenses are different from individuals convicted of mixed offenses and offline offenses against children, and their risk level can be best characterized as an intermediate between these two groups - whereas mixed offenders may benefit from conventional treatment models, CSEM offenders may have different criminogenic needs and responsivity styles.

\section{Demographic and Clinical Characteristics}

Differences between individuals convicted of Internet (online) vs. typical contact (offline) sexual offenses have been found in terms of demographic and developmental characteristics, as well as offending behaviors. In general, those convicted of Internet sexual offenses have been found to be overwhelmingly young, Caucasian males ${ }^{19-22}$. Recent studies have continued to find that individuals 
convicted of Internet sex offenses are significantly younger than their contact or mixed offending counterparts ${ }^{20,23-25}$. Additionally, individuals convicted of Internet sex offenses are significantly more likely to report their relationship status as single - as opposed to married, divorced, or separated - than individuals convicted of contact sex offenses $^{20,23-25}$. Multiple studies report that individuals convicted of Internet sex offenses generally have stable employment ${ }^{19,22}$, with Aslan and Edelmann $(2014)^{23}$ reporting they are significantly more likely to have fulltime employment than individuals convicted of contact sex offenses. Similarly, those convicted of Internet offenses are significantly more likely to have completed a higher level of education than those convicted of contact offenses such as college or postgraduate educations compared to a high school diploma ${ }^{23,26}$. In comparison to those convicted of contact sex offending, individuals convicted of Internet offenses have also been found less likely to have endured childhood sexual abuse ${ }^{23,24}$, have lower rates of substance abuse $^{20,22}$, and fewer convictions for prior offenses ${ }^{20,24,26}$.

In comparison to mixed and contact offense groups, Internet offense groups have also been found statistically more likely to offend against mixed gender victims, though this may simply be a result of the breadth of content available on the Internet ${ }^{23,24}$. A meta-analysis by Babchishin and colleagues $(2015)^{16}$ found the available literature suggests individuals convicted of Internet offenses are less likely to have access to children, though more likely to have access to the Internet, and are more likely to have sexual interest in children when compared to individuals convicted of contact offenses - consistent with the idea that motivated individuals will offend in accordance with the opportunities available to them. Additionally, those convicted of Internet offenses are less likely to be antisocial, tend to have greater victim empathy, and have fewer cognitive distortions than contact or mixed offense groups ${ }^{16,24-26}$. Some literature has also suggested that those convicted of Internet offenses are more likely to report homosexual or bisexual orientations than contact or mixed offense groups ${ }^{16}$.

\section{Evidence-Informed Treatment Curriculum}

The differences in the demographic and clinical characteristics of the offending pathways have raised questions on the unique needs of these groups. The extent that those convicted of Internet sexual offenses can benefit from programs that were meant for offline offenders is unknown. I will describe our experience of implementing an evidence-informed treatment curriculum for individuals convicted of Internet sexual offenses.

\section{Method}

As a first step, our agency developed a workgroup consisting of clinical supervisors who were assigned to operationalize the necessary components of an evidenceinformed program. Discussion sessions were held on key concepts and theories, barriers and challenges, and most importantly, implementation strategies. The second step entailed conducting a search of peer-reviewed studies using combinations of the following keywords: "Internet Sex*," "Child Abuse Image*," "Child Sexual Exploitation*," "CSEM," "Child Porn*," "Indecent Images of Children," AND "Treatment*," "Intervention*," "Rehabilitation*," "Sex Offender Treatment*." Studies were identified using the following electronic databases: PsycINFO, Medline, Pubmed, and Web of Knowledge. The contents of each article were reviewed and indexed based on their relevance to the assessment and treatment of individuals convicted of Internet sexual offenses. Books, particularly Internet Sex Offenders ${ }^{27}$, were used as well. We studied available material from the Internet Sex Offender Treatment Program ${ }^{28}$ and the FCI Butner Sex Offender Treatment Program (https:// www.youtube.com/watch?v=P8FmrdtDo8I). We used information from the following websites: Center for Sex Offender Management (CSOM; https://cepp.com/centerfor-sex-offender-management-csom/) and online PROTECT (https://onlineprotect.org.uk/). We also collaborated and consulted extensively with Professor Derek Perkins and Dr. Hannah Merdian, the authors of online PROTECT, as well as with Dr. Eke and Dr. Seto. Finally, we attended Research and Treatment Conferences sponsored by the Association for the Treatment of Sexual Abusers (ATSA) and sought out paper, symposium, and poster sessions that were relevant to Internet sexual offending.

\section{Operationalizing Key Concepts and Theories}

Evidence-informed: Nowadays the term 'evidencebased' has become a popular term that is used broadly, but without specificity on the level of evidence. For example, a prison rehabilitation program called Insight Garden Program, includes the following statement on its website: "we are an evidence-based program, with a less than $10 \%$ recidivism rate (rate of return to prison) which results in the healing of lives, families, and communities." ${ }^{29}$. The program is likely to have therapeutic benefits, including increase in engagement and motivation to change, but where the evidence is derived for this program is unclear. The 'gold standard' to determine a program's effectiveness is a double-blind, randomized, controlled trial where an outcome from one treatment is compared to an outcome from a controlled treatment. Although double-blind studies are nearly impossible in psychotherapy outcomes, randomized non-blinded controlled trials are the preferred method for verification of evidence-based interventions.

We adapted the term evidence-informed to signify that our program relied on the existing literature in combination with the experiences and expertise of our clinical team. This is consistent with the literature that argues that "evidence- 
based" and "evidence-informed" do not denote the same thing and should not be used interchangeably ${ }^{30,31}$. We aimed to make clear that workgroup members and organization administrators understand that evidence-based implies data in effectiveness - or in this context - reduction in recidivism. To the best of our knowledge, no program has yet shown or examined what works in reducing recidivism among Internet sexual offenders. Therefore, treatment programs designed for Internet sexual offenders can be best characterized as research-informed.

Child Pornography, Indecent, or Abuse Images, and Child Sexual Exploitation Material: There are concerns and objections in the field on the use of the term "child pornography" 32 . Children cannot consent to sexual activity, and the content of the material is considered equivalent to crime scene photos or films of children being sexually abused or exploited. As such, indecent or child abuse images would more accurately reflect what these images portray. However, given that Internet offenses against children are not limited to images or films, and may include stories, solicitation, and we favored using child sexual exploitation material (CSEM), which encompasses a wider group of offenses. It is worth acknowledging CSEM is also not an all-inclusive term, and leaves open questions on situations where an individual may use the Internet to read about sex tourism and travel to a particular country to sexually abuse children. However, given that the majority of clients in our program were convicted of child abuse images, the use of CSEM was considered a good fit. We limited the use of the term child pornography to contexts where it would be awkward or confusing to avoid - for example, referencing articles where the term was used originally, names of assessment tools, or items within a risk assessment tool.

\section{Development and Implementation of the Treatment Curriculum:}

Risk Assessment: A central issue in program development was choosing a risk assessment tool for estimating the likelihood of committing a sexual offense in the future, as well as for guiding treatment decisions. There are multiple limitations in the availability of suitable risk assessment tools for individuals convicted of Internet sex offenses, including considerations for the specificity of Internet offenses, short follow-up periods, and small sample size.

There are two commonly used actuarial risk assessment tools for individuals convicted of Internet sex offenses: The Risk Matrix-2000 ${ }^{33}$ (RM2000) and the Child Pornography Offender Risk Tool ${ }^{34}$ (CPORT). The RM2000 is a statistically-derived risk assessment tool intended for males aged at least 18 years who have been convicted of a sexual offense ${ }^{33}$. The tool was developed in the United
Kingdom with males aged 18 years and older who were convicted of a sexual offense after the age of 16 . An Internetonly offense group was not included in the original sample, but has been present in subsequent samples ${ }^{35,36}$. The international version scoring manual provides guidance on how to use RM2000 with Internet-only offense groups. Briefly, static information is used to classify individuals into four different risk bands for sexual (RM2000/Sexual) or other violent offenses (RM2000/Violence), which is representative of that group's likely rate for reconviction of future sexual offenses. The RM2000/Sexual scale consists of seven items: age, sexual offending history, criminal (nonsexual) offending history, sexual offense against a male victim, sexual offense against a stranger, having a twoyear live-in romantic relationship, and non-contact sexual offense history. The scoring algorithm for the international version is a two-step process. Step 1 involves summing the first three items and translating the score into one of the following risk categories: below average, average, above average, or well-above average. Step 2 involves summing the last four items, and then using that score to shift the initial risk category one or two levels upward. If two or three of these items are present, the initial risk category is raised one level (e.g., from below average risk to average risk). If all four of these aggravating factors are present, the initial risk category is raised by two risk levels (e.g., from average risk to well-above average risk).

Barnett and colleagues (2010) ${ }^{35}$ examined the predictive validity of a modified version of the RM2000 scales and reported moderate (AUC $=.7$ ) predictive accuracy (albeit large confidence interval: .43 to .97) for all subgroups of sexual offending, including individuals convicted of Internet offenses (making or possessing indecent images of children). These findings, however, are not consistent across all studies. Wakeling and colleagues $(2011)^{36}$, for example, reported poor predictive validity (AUC $=.5$ ) for sexual reconviction among those convicted of Internet offenses only, and moderate accuracy for those convicted of mixed offenses. Overall, findings indicate that modified versions of RM2000 are relevant for better understanding recidivism among individuals convicted of Internet sexual offenses, but a tool designed specifically for this population has yet to be developed.

The Child Pornography Offender Risk Tool (CPORT) ${ }^{34}$ is a more recently developed structured risk assessment tool used to assess the likelihood of future offending in men convicted of CSEM possession. The scoring manual and updated reference material for the CPORT are available online through Research Gate: https://www.researchgate. net/project/Child-Pornography-Offender-Risk-ToolCPORT. The CPORT consists of seven items: age at the start of the police investigation, prior criminal history, prior or concurrent contact sexual offending, prior or concurrent 
failure on conditional release, evidence of pedophilic or hebephilic sexual interests, more boy than girl child pornography content, more boy than girl other child (e.g., nude) content. The Correlates of Admission of Sexual Interest in Children (CASIC) ${ }^{37}$, a separate questionnaire consisting of six items, can be used to supplement scoring for evidence of pedophilic or hebephilic sexual interests. CPORT items are summed for a total score that can range from zero to seven. Combining results from the development and validation samples, the CPORT has demonstrated good predictive accuracy for five-year sexual recidivism and online recidivism ${ }^{34}$. At present, there is insufficient research to assign risk level for CPORT scores, and interpretation of scores is limited to percentile ranking. Recidivism probability estimates from logistic regression for five-year time frames may also be used, but the stability of these are unknown.

While static risk assessment tools estimate risk level and likelihood of recidivism, dynamic risk factors identify treatment targets that are amenable to change. Comprehensive risk assessment involves combining both static and dynamic targets in a structured, or empirical manner. There are currently no validated risk assessment instruments specific to the treatment needs of individuals convicted of Internet sex offenses, and whether the available tools address the needs of all sexual offending groups remains an open question. The Stable- $2007^{38}$ and the Sex Offender Treatment Intervention \& Progress Scale (SOTIPS) ${ }^{39}$ are two of the commonly-adopted dynamic risk assessment tools for individuals convicted of Internet sexual offenses.

The Stable- $2007^{38}$ consists of 13 items (significant prosocial influences, negative emotionality, social isolation, intimacy deficits, impulsivity, problem-solving skills, lack of concern, hostility towards women, sexual self-regulation, sexual deviance, sexual preoccupation, emotional identification with children, and cooperation with supervision) organized under five sections: social influences, intimacy deficits, sexual self-regulation, general self-regulation, and cooperation with supervision. Total scores on the STABLE-2007 can range from 0 to 26 for individuals with child victims and 0 to 24 for individuals without child victims. The total score can be classified into three risk categories: low $(0-3)$, moderate $(4-11)$, and high (12). However, the Stable-2007 manual uses the following precautionary language for use with individuals convicted of child pornography-only offenses: a) the tool may be used as a clinical guide to identifying treatment needs and supervision targets, b) the tool should not be used to estimate recidivism rates or to assign nominal risk categories, and c) users should explicitly acknowledge that the tool is not validated for child pornography-only offense groups. A recent meta-analysis that included a sample with a high number of CSEM-exclusive male subjects found the STABLE-2007 to have good predictive accuracy for a new child pornography offense ${ }^{40}$. These preliminary findings are promising to further investigate the generalizability of the Stable-2007 items to individuals convicted of Internet sex offenses.

The second commonly-used risk assessment tools for CSEM clients - SOTIPS - consists of 16 items (sexual offense responsibility, sexual behavior, sexual attitudes, sexual interests, sexual risk management, criminal and rule breaking behavior, criminal and rule breaking attitudes, stage of change, cooperation with treatment, cooperation with community supervision, emotional management, problem solving, impulsivity, employment, residence, and social influences) that are inclusive of sexual and general criminal offending. The items are organized under six sections: sexuality and risk responsibility, criminality, treatment and supervision cooperation, self-management, social stability, and support. The SOTIPS manual rules on target population is similar to the Static- $99 R^{41}$, where there is a distinction between category A and category $\mathrm{B}$ sex offenses, with possession of child pornography falling under the latter and not meeting the scoring criteria. The authors have adopted a precautionary use of the test for CSEM clients that is consistent with the Stable-200740.

Another tool that might be relevant, especially in differentiating CSEM clients with and without nonsexual criminal histories, is the Level of Service/Case Management Inventory (LS/CMI) ${ }^{42}$. The LS/CMI consists of 43 questions grouped into eight criminogenic needs sections: criminal history, employment/education, family/marital, leisure/ recreation, companions, attitudes, alcohol/drugs, and antisocial patterns. While no research has directly examined the utility of SOTIPS or LS/CMI for identifying treatment needs in clients with CSEM-exclusive offense histories, the validation studies included a wide range of offending groups, including those with CSEM offenses.

Finally, the Kent Internet Risk Assessment Tool-243, although not commonly used in forensic evaluations, is used to assist law enforcement agencies with case prioritization and workload investigations. Reportedly, it aims to identify, individuals who represent the highest risk of contact offending by prioritizing those who share features with mix offenders. The items are organized into four evaluation steps: previous behaviors, access to children, current behavioral facilitators, and other factors. To the best of our knowledge, a risk assessment tool that could be used to identify online offenders who will re-offend by committing a contact sexual offense is not yet available.

In our clinical setting, we have implemented the use of the CPORT along with the Stable- $2007^{40}$ or SOTIPS during the intake process. The decision process in selecting these 
tools was not as systematic as it could have been. In hindsight, using principles from organizational decision-making could have saved us a lot of time and positively affected the perceived credibility of clinicians toward the organizational leadership. We went back-and-forth on our decisions, eliciting criticism for being indecisive. Nevertheless, the final selection of the instruments, was made according to the peer-reviewed literature, availability of the test developers to consult and offer training opportunities, and consensus within the organization clinical leadership. It is worth pointing out that access to the literature, especially for nonacademic organizations, is equally important as the published literature itself. For example, the CPORT/CASIC Project Page on ResearchGate facilitated networking with others, finding training handouts and other resources, accessing articles, and having updates about published studies using the CPORT.

One challenge that our organization encountered is its lack of risk categories, therefore making it difficult for clinicians to report risk in a conventional format. Although the scoring guide includes information on the distribution of scores - specifically, where raw scores may be in terms of percentiles - this is not always as intuitive to interpret for some of our colleagues in the criminal justice system Consequently, the RM2000 ${ }^{36}$ is used whenever a clinician must render a decision about risk level. LS/CMI is used as clinically needed, typically when the client has a history of nonsexual offenses, and/or when the identification of antisocial behavior, attitude, and patterns are relevant for case formulation. Clinicians and colleagues at large have provided favorable feedback in the use of these measures to determine risk and identify targets for intervention.

\section{Theoretical Framework}

Our treatment framework was based on the work of Merdian et al. (2018) ${ }^{44}$, which through the use of interviews and thematic analyses, had identified seven subordinate themes affecting an individual's pathway to CSEM offending. Brief descriptions of these seven pathways are described in Table 1. These themes were structured into seven treatment modules that included a clinical guide, client handout, and sample goals and objectives. The program also included integration of etiological models that considered offending behavior as a consequence of motivational and facilitative factors ${ }^{45-48}$. Principles from other theoretical models of sexual offending, such as Ward and Siegert's (2002) ${ }^{49}$ Pathways Model, Marshall and Barbaree's (1990) ${ }^{50}$ Integrated Theory of Child Sexual Abuse, and Yates \& Prescott's (2011) ${ }^{51}$ Good Lives Model, were adopted as well.

The rationale for choosing Merdian et al. (2018) ${ }^{44}$ pathways model over other approaches was because it

Table 1. Seven Pathways of Sexual Offending (Merdian et al., 2018) (4 $^{44}$

\section{Pathway}

The Developmental Context

Individual Propensities and Psychological Vulnerabilities

The Internet Environment and Behavior

Personal Circumstances

Permission-Giving Thoughts

The Consequences for the Individual

Desistance

\section{Description}

This pathway refers to key learning experiences from developmental years that could be considered distal factors contributing to eventual offending behavior. This pathway can be broken down into two subthemes: lack of connection with others and a vulnerability to socio-emotional breakdown - such as poor familial relationships - as well as the role of sexual needs within and separate from intimate relationships - which may include childhood sexual abuse or early exposure to pornography.

This pathway refers to the main motivational and facilitative psychological vulnerabilities that have been found to be directly linked to CSEM offending behavior. These may include negative internal states such as continued reinforcement of low self-esteem - reliance on dysfunctional coping skills, and/or an underlying sexual interest in children.

This pathway refers to the role of the online environment as a situational facilitator of the offending behavior. Two subthemes predicate this, the first being the nature of the Internet - in terms of accessibility and anonymity - and the second being the psychological meaning of the offending behavior - such as the act of searching for this material, as well as chatting/sharing with other CSEM-involved individuals.

This pathway refers to an individual's circumstances directly proceeding their initial CSEM offending behavior. This is often a lack of social connection or sexual outlet, the breakdown of a relationship, general feelings of failure, or another significant life stressor.

This pathway refers to cognitions that lower inhibitions toward the CSEM offending behavior and are perceived as reinforcers for continuing to offend. Specific thoughts are often that the offending behavior is not harmful, that it is simply a victimless crime, and/or that the content does not depict real children.

This pathway represents experiences directly following the offending behavior, which is in response to negative perceptions of the individual's personal circumstances and the inability to cope. This can be divided into two subthemes, the first described as a negative reinforcer - such as viewing this behavior as an escape from everyday life - and the second as a positive reinforcer - such as viewing this behavior as a means of sexual gratification and connection.

This pathway supports the idea that individuals may have engaged in attempts to self-manage their offending behavior prior to arrest. This falls into two subthemes: increased social engagement - such as elevated self-confidence or ability to engage socially - and confidential help and education - such as relabeling the content as child abuse images instead of child pornography. 
integrated offense-related vulnerabilities and personal circumstances within the Internet environment. It also provided the flexibility for structuring the program into a preexisting setting (e.g., group hours, number of sessions, individual and group meetings), instead of the other way around.

\section{Case Study}

A fictitious case is presented to demonstrate the intricacies of the treatment program where an assessment of risk, criminogenic need, and responsivity factors are examined in the framework of the pathways model.

Offense Summary: Mr. Musa is a 40-year-old male who was convicted of (Count 1) Shipping Material Involving the Sexual Exploitation of Minors and (Count 2) Possession of Material Involving the Sexual Exploitation of Minors. A postal inspector was conducting an undercover Internet operation focusing on individuals trafficking child sexual exploitation material via the Internet and United States mail. Mr. Musa contacted the postal inspector via email after seeing his message posted through Yahoo! Groups which stated that the undercover inspector had some "action photos" of subjects in their early teens and younger. The postal inspector provided graphic descriptions of available videos, and Musa responded with four image files of prepubescent males engaged in sexual conduct and a request for one of the tapes from the postal inspector's list depicting 12-year-old baseball players and cheerleaders engaged in sexual conduct. Mr. Musa also offered to trade “a DVD for a DVD." Over the following days, Mr. Musa continued to email the undercover postal inspector child sexual exploitation images, particularly prepubescent male content, and also let him know that he had sent the postal inspector a DVD in the mail with a two-hour reel of sexually explicit photos and short video clips. Once the postal inspector received the DVD one week later, it was reviewed and discovered that the DVD contained approximately 700 images and 40 videos. Out of these, 85 images and 15 videos were determined to constitute child sexual exploitation material. These files depicted primarily prepubescent males, some as young as five years of age, engaged in sexual conduct with other prepubescent males or adult males, including acts of fondling and anal penetration.

Two weeks later, the postal inspector reinitiated contact with Mr. Musa, and they exchanged emails for one month before Mr. Musa indicated he was once again interested in trading child pornography, and that "LimeWire" and "Bearshare" were good sources. One week later, a warrant was obtained authorizing the search of Mr. Musa's residence. The postal inspector alerted Mr. Musa that he would be receiving a DVD in the mail. When the package arrived at his home and he signed the delivery receipt, postal inspectors appeared and began their warrant search. Mr. Musa admitted to officers that he began viewing child sexual exploitation content in approximately 1999, and that he considered himself as "being someone who is addicted to looking at these images" and that he found them to be "a thrill to watch." He denied engaging in any sexual contact with a minor. Mr. Musa was ultimately held responsible for being in possession of $600+$ images of child sexual exploitation material.

Prior to the index offense, Mr. Musa had no juvenile or adult court adjudications. He currently reports that his index offense was a misunderstanding, and that he was not aware of the illegality of child sexual exploitation materials at the time he was viewing it. He believed that since it could be so easily accessed online, especially back in the early years of the Internet, that it must be regarded like any other adult pornography. He restates that it began in 1999 when he was searching for adult pornography images. After visiting a website, he claims to have received an email with a link to an additional pornography site. Out of curiosity, he viewed the site and was surprised to find images of children. He believed the children in the images were willing participants, and that viewing the content was a victimless action. He adamantly asserts that had he not received the link to this website, and were it not so easily accessible online, he would otherwise never have viewed this kind of material. He admits to having fantasized and masturbated while viewing the child abuse images.

Social History: Mr. Musa was raised by his two parents and has five siblings. He states he was raised in a positive family environment, and that he always shared a close relationship with his parents and siblings. Both of his parents maintained steady employment, and their financial situation was consistently stable. Mr. Musa denies experiencing any mental or physical abuse during his childhood.

Mr. Musa reports a normal academic progression through elementary, middle, and high school with no difficulties, never having received any special education services. In fact, he reports he always felt ahead of his peers, often receiving top grades without having to put in considerable effort. Because of this, he felt that he never had any close or real friendships during his school years and described all of his social relationships as mere acquaintances. Mr. Musa graduated from high school and subsequently attended some community college, having enrolled in photography and health classes out of personal interest. However, he chose not to pursue any kind of degree.

Between the ages of eight and 11, Mr. Musa reports having sexual "connections" with a male cousin in his twenties. Mr. Musa never spoke about this experience until 
the index offense, and by that time the cousin had passed away. At the time, he did not perceive these acts as sexual abuse or exploitation, and does not recall feelings of shame, fear, or distrust of adults. Mr. Musa now understands the abusive nature of these acts, but he neither feels resentment toward his cousin, nor thinks of himself as a victim of sexual abuse. Mr. Musa does not believe this experience caused him to seek child sexual exploitation images, but he could see how it may have affected his deviant attitude towards this content, that viewing these images was harmless.

Mr. Musa reports his first consensual sexual interaction was at the age of 18 , and the first time he had sexual intercourse was at the age of 21 with a girlfriend of approximately six months. Mr. Musa has been in brief relationships with women and men of his own age, never lasting more than 12 months. He identifies his sexual orientation as same sex, and explains that his previous romantic experiences with women were obligations to please his family. Although he enjoys strong ties with his parents and siblings, he continues to maintain his sexual orientation as a secret. He believes disclosure of his sexuality would be another disappointment to his family and feels he has already put them through enough upset. Mr. Musa reports that he has never been married, has fathered no children, and is presently single.

Mr. Musa reports maintaining steady employment since attending community college, and prior to his arrest, he spent 17 years working for a division of a popular chain grocery store. Although a senior employee, Mr. Musa reports dissatisfaction with his salary. He felt he was not receiving the payment he deserved at that point in his career and noted that he did not receive any kind of raise or promotion during the last three years of his employment. Mr. Musa was terminated from this job due to the index offense.

Mr. Musa reports his first interactions with alcohol at age 17, however, he did not enjoy the feeling of being "out of control" and only continued to consume it in order to ease anxiety in social situations. He reports consuming one-to-four alcohol drinks once or twice monthly. $\mathrm{He}$ admits to using marijuana about once a year, which began approximately five years prior to his index arrest. Mr. Musa has no other drug use history.

Mr. Musa reports that his lack of substantial friendships in childhood caused him a lot of loneliness and anxiety as he has entered his adult life. However, he never attended any mental health treatment for this. No other mental illnesses run in his family, to his knowledge. In terms of physical health, he currently suffers from Type II diabetes, acid reflux, and chronic pain due to repetitive movements that are in the beginning stages of arthritis.

\section{Risk Factors}

The Child Pornography Offender Risk Tool (CPORT):

The CPORT is a seven-item structured tool to assess the likelihood of future sexual offending over a 5-year fixed follow-up. The items include: age 35 or younger at index offense, any prior criminal history, any prior or index contact sexual offense history, any conditional release failure, admission of pedophilic or hebephilic sexual interests, greater content featuring boys as compared to girls in child pornography viewed/possessed, and greater content featuring boys as compared to girls in other/nude child materials viewed/possessed. Mr. Musa presents with 3 out of 7 risk indicators: admission of pedophilic interests, and more boy-focused content in both child pornography material, as well as nude/other child material.

For a person with this score and no contact offense history, the observed five-year recidivism rate is $12.2 \%$ for any sexual offense and for any child pornography offense. In the combined normative dataset from Eke et al. $(2019)^{52}$, roughly $15 \%$ of individuals had the same CPORT score, $69 \%$ had a lower score, and $16 \%$ had a higher risk score. In other words, out of 100 individuals involved with child pornography material, 69 would be expected to have a lower score, 15 would have the same score, and 16 would have a higher score.

RM2000. Mr. Musa's risk for sexual recidivism was also assessed using RM2000, a static actuarial risk assessment tool. It is worth pointing out that the reason for proctoring RM2000 was to derive a risk level. The RM2000 items include: age, sexual offending history, criminal (nonsexual) offending history, sexual offense against a male victim, sexual offense against a stranger, single, and non-contact sexual offense history. Mr. Musa's history places him in the Average category on the Sexual-Scale (Revised), where he obtained a total score of 2 for sexual offense against a male victim and single status.

\section{Need Factors}

STABLE-2007. The STABLE-2007 measures empirical risk factors that are routinely addressed as part of correctional rehabilitation (i.e., criminogenic needs) for adult males convicted of sexual offenses against a child or non-consenting adult. The STABLE-2007 consists of 13 items related to psychological, interpersonal, and sexual functioning, that are added together to create a total score. No current research has examined the extent to which the STABLE-2007 provides accurate assessment of criminogenic needs among men whose only sexual convictions involve possession of indecent images of children. The STABLE-2007 was used as a clinical guide for identifying treatment needs and supervision targets. 
The following need areas have been identified as being of SIGNIFICANT CLINICAL CONCERN for Mr. Musa: Capacity for Relationship Stability, General Social Rejection, and Deviant Sexual Preferences. The following need areas have been identified as being of SOME CLINICAL CONCERN: Sex Drive/Preoccupation and Sex as Coping.

Level of Service/Case Management Inventory (LS/ $\mathrm{CMI}$ ). The LS/CMI is an instrument that measures the risk and need factors of convicted adolescents and adults. It is used to aid in the treatment planning and management of individuals in correctional related agencies. Mr. Musa obtained a LS/CMI Section 1 TOTAL Score of 5. His risk/ need level is low. The following areas were assessed as having the most concerning level of risk and needs and should be primarily targeted in treatment and supervision: currently unemployed and absence of recent participation in an organized activity.

\section{Protective Factors}

Mr. Musa has the benefit of some protective factors, including a positive and stable relationship with his parents and siblings, who have all remained supportive of him throughout the offense. Despite some reliance on alcohol in social situations, there are no historical indications of alcohol or drug dependence. Additionally, Mr. Musa demonstrates satisfactory compliance and understanding of his supervision conditions and the Courtmandated treatment requirements. Mr. Musa is currently unemployed, but he has a stable work history and is actively seeking employment. He considers work and financial independence as an important aspect of his identity.

\section{Risk Level}

In the absence of research to combine static and dynamic risk factors to derive a single risk level, reliance on RM2000 along with his problems relative to sexual deviance and poor interpersonal competence have been used to assess his overall risk level. Mr. Musa appears to be at an average risk of reoffending. He has few identifiable criminogenic needs and is expected to respond positively to services. Eighteen months of individual psychotherapy is recommended: weekly sessions for the first 12 months, and a decrease to twice a month for the last six months. This would be equivalent to approximately 60 hours of therapy.

\section{Responsivity Factors}

Mr. Musa finds the therapeutic process helpful in facilitating self-awareness and making changes. His motivation to reflect, present, and provide and take feedback is high. Mr. Musa's beliefs about human sexuality are deeply rooted in cultural norms and expectations. He may also be sensitive to a therapist's cultural awareness and his/her ability to address issues without assumptions and judgments.

\section{Case Formulation}

Developmental Context: Mr. Musa reports growing up in a secure environment with responsive and warm caregivers. Despite a positive family environment, from a young age, Mr. Musa has felt inadequate in his social abilities and experiences difficulties in forming lasting relationships. The treatment goal for this theme would be for Mr. Musa to identify the strengths and challenges of attachment experiences, and their impact on his adult relationships. Treatment objectives may include: a) processing childhood feelings and memories associated with his primary caregiver, b) processing his desire and ability to trust others, as well as demonstrating himself as trustworthy, c) reflecting on how strong ties with his parents may generalize to feelings of security in adulthood, d) exploring the importance and value placed on relatedness, and e) identifying the activities involved in achieving relatedness.

Individual Propensities/Psychological Vulnerabilities: Mr. Musa's motivation for online offending could be hypothesized as stemming from sexually deviant fantasies and interests. It is worth noting that he was engaged in the viewing and possession of these images for over six years, a substantial devotion of time, energy, and interest. Feelings of loneliness and anxiety, as well as the inability to establish emotional and sexual relationships with ageappropriate adults, may have facilitated these offending behaviors. Sexual preoccupation and his own sexual victimization as a child are also likely to have increased the risk of offending. The treatment goal for this theme would be for Mr. Musa to develop an understanding of how individual propensities and psychological vulnerabilities increase one's risk of offending, especially when combined with dysfunctional coping skills. Treatment objectives may include: a) participation in the assessment of sexual interests using psychophysiological measures, b) exploration of childhood experiences that may trigger and maintain his sexual interest in children, c) reflection on the consequences of his sexual interest in children, d) consultation with a psychiatrist and exploration of the use of medication to reduce sex drive, and e) identification of ways in which his sexual interest in children may have been related to seeking common life goals.

Internet Environment: Accessibility, affordability and anonymity, commonly known as the "Triple-A Engine," of the Internet permitted the acceleration of Mr. Musa's online offending behavior. He recalls he relied more and more on the Internet throughout his index offense for interpersonal needs and the regulation of negative emotions associated with his loneliness. He reports frequently turning to the Internet to escape from the pressure and discomfort of his life at the time. Additionally, his perception of anonymity 
through the Internet contributed to risky explorations, such as seeking younger images. He felt more emboldened to act on his natural interests and dispositions. The treatment goal for this theme would be for Mr. Musa to develop the knowledge and skills necessary to manage his online behavior. Treatment objectives may include: a) sharing thoughts and feelings on using the Internet to escape from his negative feelings, b) reflecting on the role that anonymity, accessibility, and affordability played in his online interactions, c) eliciting feedback on whether his online behavior fits the self that is presented in the group, d) building an empathic response in recognizing children in the images as victims of child abuse, and e) developing and implementing strategies to block or avoid high risk sites.

Personal Circumstances: At the time of the index offense, Mr. Musa reports experiencing persistent feelings of inner emptiness and dissatisfaction with his employment situation. One particular life event that occurred close to the time of the offense was a loss in a jobrelated promotional opportunity. He states that he viewed himself as a failure with a dead-end job and no prospects for a career. This experience was generalized to other aspects of his life, especially interpersonal needs, where he felt that he was incapable of developing and maintaining intimate relationships. He resorted to dealing with these emotions primarily through the viewing of pornography and masturbation, which ultimately amplified his risk for seeking illegal images. The treatment goal for this theme would be to raise his awareness on how life event(s) are influenced by schemas. Treatment objectives may include: a) reflecting on what other significant things were going on in his life, b) identifying and processing of self-defeating statements that may recur throughout his life, c) building alternative beliefs replace maladaptive schemas, and d) developing a visual picture of possible healthy coping responses.

Permission-Giving Thoughts: Mr. Musa's reported thinking patterns that facilitated his offending behavior reflect denial and disbelief in his role of child abuse. He remembered telling himself that viewing the images caused no harm to the children, that there was no direct physical contact and the children in these images did not reveal any distress or indication of sexual abuse, and even that the children in the photos were smiling and appeared to be enjoying themselves. The treatment goal for this theme would be to explore how these thoughts might have aided to justify his offending behavior. Treatment objectives may include: a) developing a list of his permission-giving thoughts, b), exploring the origins of his permission-giving thoughts, c) reframing these permission-giving thoughts through alternative explanation, and d) seeking input from group members to shift absolute thinking patterns into something more balanced.
The Consequences for the Individual: Mr. Musa's reaction toward his offending behavior seems to have changed from a positive mood and feelings of excitement, to overwhelming dread and the exacerbation of his loneliness. He said the best way that he could describe the process was a loss of control. The treatment goal for this theme would be to learn how to use his strengths in pursuit of prosocial pleasurable activities. Treatment objectives may include: a) completing the Values in Action inventory of strengths, b) developing a list of activities to use his signature strengths to their fullest potentials, c) using his signature strengths in novel ways, and d) developing a tolerance for a certain degree of negative mood and boredom.

Desistance: Mr. Musa has a positive bond with treatment providers, and as he likes to say, the "collective wisdom" of the group. He feels that reflections and feedback from other members have provided him with the tools to understand and regulate his own thoughts, emotions, and behaviors. The treatment goal for this theme would include further developing desistance strategies. Treatment objectives may include: a) preparing to tell his life story with an emphasis on his crime-free identity, b) developing a list of potential barriers to desistance and his strategies to overcome these barriers, c) exploration of prosocial activities or programs to develop his sense of belonging, and d) commitment to developing a good life that is free of sexual offending.

\section{Staff Training and Development}

Staff training and continuous professional development both play a key role in the implementation of new programs. Our first strategy was to ensure there were manuals and materials available for the new program. We developed clinical guidelines, client handouts, group activities and exercises, as well as sample treatment goals and objectives that corresponded to each offending pathway. These materials were organized and made available through an internal SharePoint site. Trainings were provided both face-to-face and through livestream, as well as prerecorded webinars. Experts in the field were invited to train staff in the area of risk and treatment of online sexual offending. These trainings were received well and followed by enthusiastic question-and-answer sessions. Staff rated case examples and practical information as the most pragmatic features of these trainings. Common feedback from clinicians included a desire for "less theory and more practical information." We also provided regular internal trainings. Anecdotal feedback from staff seemed to suggest that one-to-one interactions with supervisors who were informed and excited about the new program were critical in their implementation efforts. Although we had assessments in place to measure staff members' pre-andpost knowledge, skills, and attitudes, regretfully we were unable to follow through with a systematic evaluation. 
Nevertheless, efforts are being made to continue to evaluate training outcomes with new employees.

\section{Research and Program Evaluation}

A major challenge in implementing a new program involves attaining organizational consensus, as well as a commitment to research and program evaluation. Three research areas that would be necessary to advance the program from research-informed to evidence-based treatment are: fidelity evaluation, client feedback, and recidivism outcomes. Fidelity measures that incorporate the clinician's own expertise and style, while still adhering to the core theory and principles of the program, is essential to evaluate the effectiveness of the program. Client feedback gauged through surveys or other processes could inform program administrators and clinicians about clients' perceptions and experiences, especially what they may have found most or least beneficial. Finally, there is a need for outcome research using a Randomized Controlled Trial (RCT), otherwise, we will never achieve consensus on 'what works' in the rehabilitation of individuals convicted of Internet sexual offenses, or arguably, whether low risk clients need any treatment.

\section{Conclusions}

I hope our experience in the development and implementation of this program will encourage others to explore new ways of integrating research into their practice. The experts with whom we have had the privilege of consulting and collaborating have inspired us to do our best and always question the merits of our decisions. We continue to have dialogues with program administrators and clinical justice partners in support of research and program evaluation. Recently, a doctoral student in Clinical Psychology from Royal Holloway, University of London, attained approval to conduct a program evaluation to explore whether individuals who participate in our program consider it helpful, and if so, in what ways. We encourage our colleagues to promote evaluation of their treatment programs and take steps toward developing an evidence-based program for online offending.

\section{References}

1. Kemp S. Digital 2019: Global Digital Overview - DataReportal - Global Digital Insights. 2019. Retrieved from https://datareportal.com/ reports/digital-2019-global-digital-overview

2. Cooper A. Sexuality and the internet: Surfing into the new millennium. CyberPsychology \& Behavior. 1998; 12): 187-193. doi: 10.1089/ cpb.1998.1.187

3. The Internet Watch Foundation Annual Report. The Why. The How. The Who. And the Results. 2019. https://www.iwf.org.uk/sites/ default/files/reports/2020-04/IWF_Annual_Report_2020_Low-resDigital_AW_6mb.pdf

4. National Center for Missing and Exploited Children. About NCMEC. 2020. Retrieved from https://www.missingkids.org/footer/media/ keyfacts
5. Department of Justice Office of Public Affairs. South Korean National and Hundreds of Others Charged Worldwide in the Takedown of the Largest Darknet Child Pornography Website, Which was Funded by Bitcoin. 2019. https://www.justice.gov/opa/pr/south-koreannational-and-hundreds-others-charged-worldwide-takedownlargest-darknet-child

6. Wolak J, Finkelhor D, Mitchell K. Child pornography possessors: Trends in offender and case characteristics. Sexual Abuse: A Journal of Research and Treatment. 2011; 23(1): 22-42. doi: $10.1177 / 1079063210372143$

7. Beech AR, Elliott IA, Birgden A, et al. The internet and child sexual offending: A criminological review. Aggression and Violent Behavior. 2008; 13(3): 216-228. doi: 10.1016/j.avb.2008.03.007

8. Frieden T. Gonzales gives child porn "wake-up call": Attorney general issues graphic warning of online "epidemic." CNN.com Law Center. 2006. Retrieved from http://www. cnn. com/2006/LAW/04/20/ gonzales. porn/index. html.

9. Oosterbaan AG. Global symposium for examining the relationship between online and offline offenses and preventing the sexual exploitation of children. Washington, DC: Law Enforcement Projects Sub-Group (LEPSG), US Department of Justice. 2009.

10. Goodman P, Page J, Phelps M. Breaking the Pendulum: The Long Struggle Over Criminal Justice. New York, NY: Oxford University Press. 2017.

11. Cullen FT, Gendreau P. The effectiveness of correctional rehabilitation: Reconsidering the "nothing works" debate. In L. Goodstein \& D. L. MacKenzie (Eds.), The American prison: Issues in research and policy. Plenum Press. 1989; pp. 23-44.

12. Mpofu E, Athanasou JA, Rafe C, et al. Cognitive-behavioral therapy efficacy for reducing recidivism rates of moderate- and high-risk sexual offenders: A scoping systematic literature review. International Journal of Offender Therapy and Comparative Criminology. 2018; 62(1): 170-186. doi: 10.1177/0306624X16644501

13. Olver ME, Marshall LE, Marshall WL, et al. A long-term outcome assessment of the effects on subsequent reoffense rates of a prisonbased CBT/RNR sex offender treatment program with strength-based elements. Sexual Abuse: A Journal of Research \& Treatment (Sage). 2020; 32(2): 127-153. doi: 10.1177/1079063218807486

14. Hanson RK, Bourgon G, Helmus L, et al. The principles of effective correctional treatment also apply to sexual offenders: A meta-analysis. Criminal Justice and Behavior. 2009; 36(9): 865-891. https://doiorg. hmlproxy.lib.csufresno.edu/10.1177/0093854809338545

15. Seto MC, Hanson RK. Introduction to special issue on internetfacilitated sexual offending. Sexual Abuse: A Journal of Research and Treatment. 2011; 23(1): 3-6. doi: 10.1177/1079063211399295

16. Babchishin K, Hanson R, VanZuylen H. Online child pornography offenders are different: A meta-analysis of the characteristics of online and offline sex offenders against children. Archives of Sexual Behavior. 2015; 44(1): 45-66. https://doi-org.hmlproxy.lib.csufresno. edu/10.1007/s10508-014-0270-

17. Ly T, Dwyer RG, Fedoroff JP. Characteristics and treatment of internet child pornography offenders. Behavioral Sciences \& the Law. 2018; 36(2): 216-234. https://doi- 10.1002/bsl.2340

18. Babchishin KM, Hanson RK, Hermann CA. The characteristics of online sex offenders: A meta-analysis. Sexual Abuse: A Journal of Research and Treatment. 2010; 23(1): 92-123. doi: 10.1177/1079063210370708

19. Laulik S, Allam J, Sheridan L. An investigation into maladaptive personality functioning in internet sex offenders. Psychology, Crime \& Law. 2007; 13(5): 523-535. doi: 10.1080/10683160701340577

20. Webb L, Craissati J, Keen S. Characteristics of internet child pornography offenders: A comparison with child molesters. Sexual Abuse: A Journal of Research and Treatment. 2007; 19(4): 449-465. 
21. Wolak J, Mitchell KJ, Finkelhor D. Internet sex crimes against minors: The response of law enforcement. Alexandria, VA: National Center for Missing \& Exploited Children. 2003.

22. Wolak J, Finkelhor D, Mitchell KJ. Child-pornography possessors arrested in internet-related crimes: Findings from the national juvenile online victimization study. Alexandria, VA: National Center for Missing and Exploited Children. 2005.

23. Aslan D, Edelmann R. Demographic and offence characteristics: A comparison of sex offenders convicted of possessing indecent images of children, committing contact sex offences or both offences. Journal of Forensic Psychiatry \& Psychology. 2014; 25(2): 121-134. https:// doi-org.hmlproxy.lib.csufresno.edu/10.1080/14789949.2014.884618

24. Elliott IA, Beech AR, Mandeville-Norden R, et al. Psychological profiles of internet sexual offenders. Sexual Abuse: A Journal of Research and Treatment. 2009; 21(1): 76-92. doi: 10.1177/1079063208326929

25. Elliott IA, Beech AR, Mandeville-Norden R. The psychological profiles of Internet, contact, and mixed internet/contact sex offenders. Sexual Abuse: Journal of Research and Treatment. 2013;25(1):3-20. https:// doi-org.hmlproxy.lib.csufresno.edu/10.1177/1079063212439426

26. Howitt D, Sheldon K. The role of cognitive distortions in paedophilic offending: Internet and contact offenders compared. Psychology, Crime \& Law. 2007; 13(5): 469-486. doi: 10.1080/10683160601060564

27. Seto MC. Internet sex offenders. Washington, DC: American Psychological Association. 2013.

28. Middleton D, Mandeville-Norden R, Hayes E. Does treatment work with internet sex offenders? Emerging findings from the internet sex offender treatment programme (i-SOTP). Journal of Sexual Aggression. 2009; 15(1): 5-19. doi: 10.1080/13552600802673444

29. Insight Garden Program. Results. 2020. http://insightgardenprogram. org/results/

30. Melnyk BM, Newhouse R. Evidence-based practice versus evidenceinformed practice: A debate that could stall forward momentum in improving healthcare quality, safety, patient outcomes, and costs. Worldviews on Evidence-Based Nursing. 2014; 11(6): 347-349.

31. Nevo I, Slonim-Nevo V. The myth of evidence-based practice: Towards evidence-informed practice. British Journal of Social Work. 2011; 41(1): 1-22.

32. Leary MG. The language of child sexual abuse and exploitation. In Hessick, C. B. (Ed.), Refining child pornography law: Crime, language, and social consequences (pp. 109-144). Ann Arbor: University of Michigan Press. 2016.

33. Thornton D, Mann R, Webster S, et al. Distinguishing and combining risks for sexual and violent recidivism. Annals of New York Academy of Sciences. 2003; 989(1): 225-235. doi: 10.1111/j.1749-6632.2003. tb07308.x

34. Seto MC, Eke AW. Predicting recidivism among adult male child pornography offenders: Development of the child pornography offender risk tool (CPORT). Law and Human Behavior. 2015; 39(4): 416-429. doi: 10.1037/lhb0000128

35. Barnett GD, Wakeling HC, Howard PD. An examination of the predictive validity of the Risk Matrix 2000 in England and Wales. Sexual Abuse: A Journal of Research and Treatment. 2010; 22(4): 443-470. doi: $10.1177 / 1079063210384274$

36. Wakeling HC, Howard P, Barnett G. Comparing the validity of the RM2000 scales and OGRS3 for predicting recidivism by internet sexual offenders. Sexual Abuse: A Journal of Research and Treatment. 2011; 23(1): 146-168. doi: 10.1177/1079063210375974
37. Seto MC, Eke AW. Correlates of admitted sexual interest in children among individuals convicted of child pornography offenses. Law and Human Behavior. 2017; 41(3): 305-313. doi: 10.1037/lhb0000240

38. Hanson RK, Harris AJ, Scott TL, et al. Assessing the risk of sexual offenders on community supervision: The dynamic supervision project. (Vol. 5, No. 6). Ottawa, Ontario: Public Safety Canada. 2007.

39. McGrath RJ, Lasher MP, Cumming GF. The sex offender treatment intervention and progress scale (SOTIPS): Psychometric properties and incremental predictive validity with Static-99R. Sexual Abuse. 2012; 24(5): 431-458. doi: 10.1177/1079063211432475

40. Brankley AE, Babchishin KM, Hanson RK. STABLE-2007 demonstrates predictive and incremental validity in assessing risk-relevant propensities for sexual offending: A meta-analysis. Sexual Abuse. 2019. 107906321987157. doi: $10.1177 / 1079063219871572$

41. Phenix A, Fernandez Y, Harris AJR, et al. Static-99R coding rules. 2016.

42. Andrews D, Bonta J, Wormith J. Manual for the level of service/case management inventory (LS/CMI). Toronto: Multi-Health Systems. 2004.

43. Long $M$, Alison L, Tejeiro $\mathrm{R}$, et al. KIRAT: Law enforcement's prioritization tool for investigating indecent image offenders. Psychology, Public Policy, and Law. 2016; 22(1): 12-21. doi: 10.1037/ law0000069

44. Merdian HL, Perkins DE, Dustagheer E, et al. Development of a case formulation model for individuals who have viewed, distributed, and/or shared child sexual exploitation material. International Journal of Offender Therapy and Comparative Criminology. 2018. doi: $10.1177 / 0306624 \times 17748067$

45. Finkelhor D. The prevention of child sexual abuse: An overview of needs and problems. Siecus Report. 1984; 13(1): 1-5.

46. Seto MC. Pedophilia and sexual offending against children: Theory, assessment, and intervention. Washington, DC: American Psychological Association. 2008.

47. Seto MC. Research on online sexual offending: what have we learned and where are we going? Journal of Sexual Aggression. 2017; 23(1): 104-106. doi: 10.1080/13552600.2016.1251021

48. Ward T, Beech A. (2006). An integrated theory of sexual offending. Aggression and Violent Behavior. 2006; 11(1): 44-63. doi: 10.1016/j. avb.2005.05.002

49. Ward T, Siegert RJ. Toward a comprehensive theory of child sexual abuse: A theory knitting perspective. Psychology, Crime and Law. 2002; 8(4): 319-351. doi: 10.1080/10683160208401823

50. Marshall WL, Barbaree HE. (1990). An integrated theory of the etiology of sexual offending. In W. L. Marshall and H. E. Barbaree (Eds.) Handbook of sexual assault. Boston, MA: Springer. 1990; pp. 257-275.

51. Yates PM, Prescott DS. Building a better life: A good lives and selfregulation workbook. Brandon, VT: Safer Society Press. 2011.

52. Eke AW, Helmus LM, Seto MC. A validation study of the Child Pornography Offender Risk Tool (CPORT). Sexual Abuse. 2019; 31: 456-476. https://doi.org/10.1177/1079063218762434

53. Gendreau P, Smith P, French SA. The theory of effective correctional intervention: Empirical status and future directions. In F. T. Cullen, J. Wright, and K. Blevins (Eds.), Taking stock: The status of criminological theory. 2009; pp. 419-446. New Brunswick, NJ: Transaction Publishers. 